
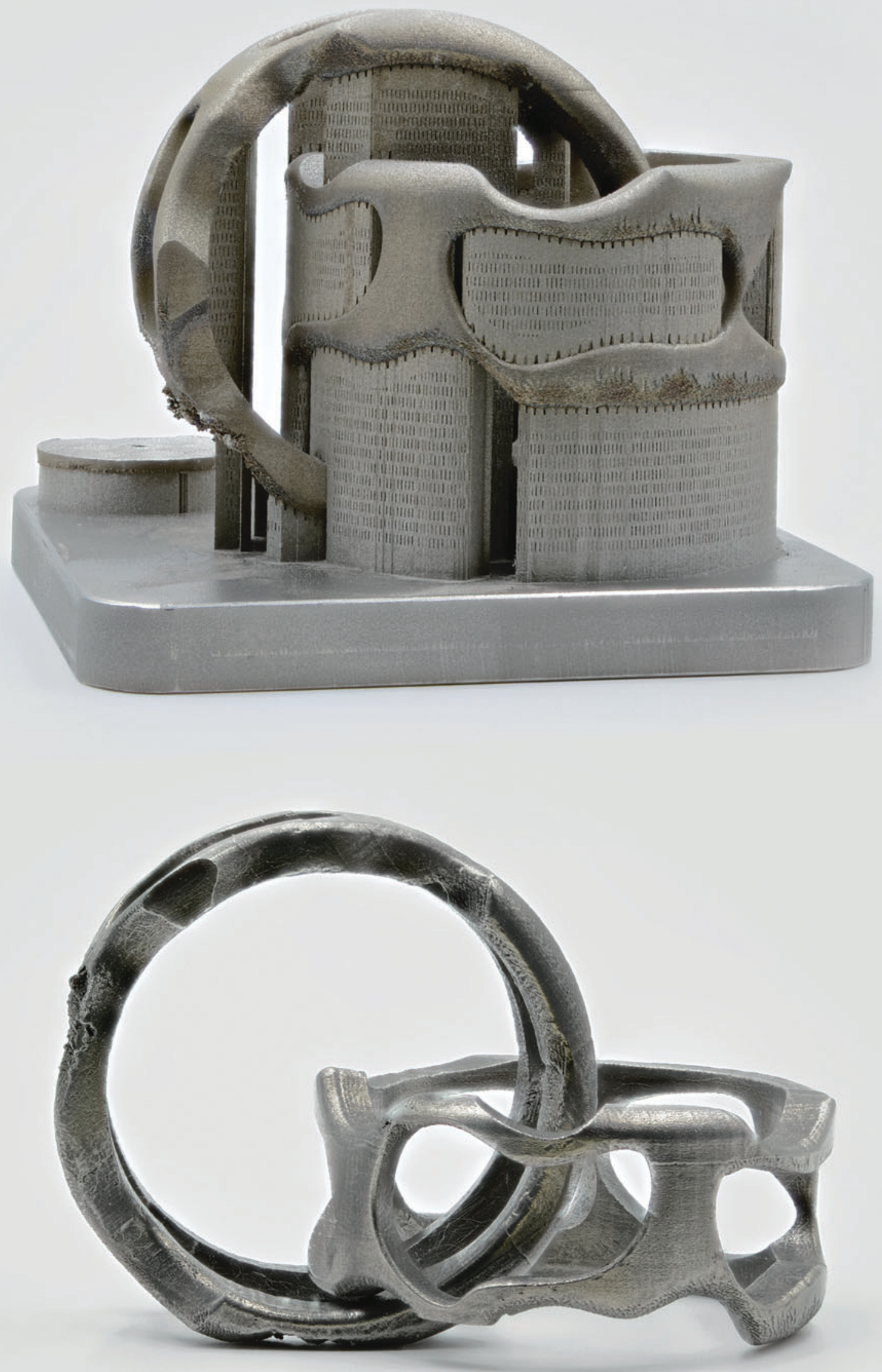


\title{
Dissolvable Supports in Powder Bed Fusion-Printed Stainless Steel
}

\author{
Christopher S. Lefky, Brian Zucker, David Wright, ${ }^{2}$ Abdalla R. Nassar, ${ }^{3}$
}

Timothy W. Simpson, ${ }^{4,5}$ and Owen J. Hildreth ${ }^{1}$

\begin{abstract}
This work demonstrates, for the first time, two approaches for dissolvable supports in powder bed fusion-printed metal parts. Expanding on our recent innovations with dissolvable supports in multimaterial direct energy deposition printing, this work brings dissolvable support capabilities to additive manufacturing systems that are limited to single-material builds. First, a direct dissolution approach is demonstrated with the supports electrochemically dissolved. While this process works, it is not self-terminating and maintaining dimensional accuracy for complex geometries is thus difficult. The second approach incorporates a sensitizing agent during the normal stress, relieving thermal annealing step to decrease the chemical stability of the top 100-200 $\mu \mathrm{m}$ of the component surface. The component is then etched under etching conditions with a high selectivity toward the "sensitized" surface over the base component material. This creates an etching process that self-terminates once the sensitized layer is removed. These two processes are first demonstrated using 17-4 PH stainless steel. Direct dissolution was conducted under anodic bias in a solution of $\mathrm{HNO}_{3} /$ $\mathrm{KCl} / \mathrm{HCl} ; 120 \mu \mathrm{m}$ of material were removed from the component's surface. For the self-terminating dissolution process, surface sensitization was done by exposing the sample to sodium hexacyanoferrate at $800^{\circ} \mathrm{C}$ for $6 \mathrm{~h}$ to carburize the top $100-200 \mu \mathrm{m}$ of the sample. This carburization process captures the protective chromium in chromium carbide precipitates and renders the surface sensitive to chemical and electrochemical dissolution. The self-terminating etching reaction was demonstrated under anodic bias in a solution of $\mathrm{HNO}_{3} / \mathrm{KCl}$. Open circuit potentials were measured at $10 \mathrm{~s}$ and $1 \mathrm{~h}$, and polarization curves were used to identify the corrosion potential. Self-termination was verified by monitoring component diameter over time, and $120 \mu \mathrm{m}$ of material were removed from the sensitized surface of the component. To further test the self-terminating sensitized approach, a set of 316 stainless steel interlocking rings were fabricated to demonstrate that this approach scales to large components with complex geometry. For these parts, this approach replaced 4-5 days of machining operations with a $32.5 \mathrm{~h}$ electrochemical bath.
\end{abstract}

Keywords: additive manufacturing, supports, steel, powder bed fusion, 3D printing, sensitization, dissolvable supports

\section{Introduction}

SUPPORT SCAFFOLDING AND STRUCTURES are an inconvenient necessity in 3D printing. These structures play an integral role in most 3D printing technologies; they mechanically anchor components to the build platform, reduce thermal stress dis- tortions, support large overhangs, and provide a thermal pathway for heat removal. ${ }^{1,2}$ Unfortunately, removing support structures can be difficult and expensive. This is especially true for 3D-printed metals, where support removal operations can negate the benefits of 3D printing. Inspired by the polymer 3D printing community's use of soluble support

\footnotetext{
${ }^{1}$ School for Engineering Matter, Transport, and Energy, Arizona State University, Tempe, Arizona.

${ }^{2}$ LeRoy Eyring Center for Solid State Science, Arizona State University, Tempe, Arizona.

${ }^{3}$ Applied Research Laboratory, Pennsylvania State University, State College, Pennsylvania.

${ }^{4}$ Center for Innovative Materials Processing through Direct Digital Deposition (CIMP-3D), Pennsylvania State University, State College, Pennsylvania.

${ }^{5}$ Mechanical Engineering and Industrial Engineering, Pennsylvania State University, State College, Pennsylvania.

Opposite page: Dissolvable metal supports for Powder Bed Fusion (PBF) printed metals demonstrated with interlocking stainless steel rings. Photo credit: Owen Hildreth.

(C) Christopher S. Lefky, et al., 2017; Published by Mary Ann Liebert, Inc. This Open Access article is distributed under the terms of the Creative Commons Attribution Noncommercial License (http://creativecommons.org/licenses/by-nc/4.0/) which permits any noncommercial use, distribution, and reproduction in any medium, provided the original author(s) and the source are credited.
} 
structures, ${ }^{3}$ we recently introduced dissolvable metal supports for multimaterial-directed energy deposition (DED)printed metals. ${ }^{4}$ In this process, stainless steel arches with $90^{\circ}$ overhangs were fabricated using low-carbon steel as a support material. Since the carbon steel has lower chemical stability compared to stainless steel, the support structure was selectively dissolved in a solution of $\mathrm{HNO}_{3}$ and $\mathrm{KCl}$ with an electrical bias applied to accelerate the dissolution process. This new process introduced the concept of selective dissolution for support removal in 3Dprinted metals and brings new capabilities to DED printing with metallic materials.

Powder bed fusion (PBF) printers are currently limited to single-material builds ${ }^{5}$ and cannot use the same multimaterial "trick" we used in DED dissolvable supports. The novelty of the work in this article lies in two new approaches that bring dissolvable support capabilities to PBF printers and other single-material printing systems. These approaches were designed to work seamlessly with existing PBF printing technologies and do not require any changes to the PBF process parameters or the metallic powder feedstock used for printing. The fundamental observation driving this work is that most support structures in PBF connect to the component over a very small region, typically 100-200 $\mu \mathrm{m}$ wide (Fig. 1). With this in mind, only a small amount of material needs to be dissolved to separate the component from the supports. If necessary, this small amount of material loss could be accounted for using simple scaling operations applied to the computer model before printing.

In our first approach, the supports are simply electrochemically dissolved. While this "direct dissolution" approach works, significant pitting damage was observed over the entire component. More importantly, it is not a selfterminating process, and controlling key process outputs (etch rate, etch depth, and pitting) could vary significantly with even minor changes in component geometry, counter electrode geometry, relative positions/orientations, electrolyte viscosity, and more. ${ }^{6,7}$

To overcome the challenges of the direct dissolution approach, we also developed a self-terminating dissolvable support process. This new approach requires no change to the PBF process parameters or metal powder feedstock and works by introducing a sensitizing agent during the standard postprint annealing step. The sensitizing agent is selected to diffuse into the sample and alter the chemical composition of the top 100-200 $\mu \mathrm{m}$ of the component's surface. The "sensitized" region is designed to be highly susceptible to corrosion/dissolution, and selecting the correct etchant and applied potential ensures that the etching reaction selfterminates once the sensitized region is dissolved. As a result, the component separates from the support in a highly controllable manner with only minor dimensional changes and little pitting.

Relative to the direct dissolution approach,the selfterminating sensitization approach requires only minor additions to the postprint annealing step and has less sensitivity to component shape, working electrode shape, or their relative orientations. Design allowances of $100-200 \mu \mathrm{m}$ can be added to the component surface to accommodate the small change in dimensions. Overall, this approach provides a much needed alternative to traditional machining and grinding operations used to remove support materials from printed
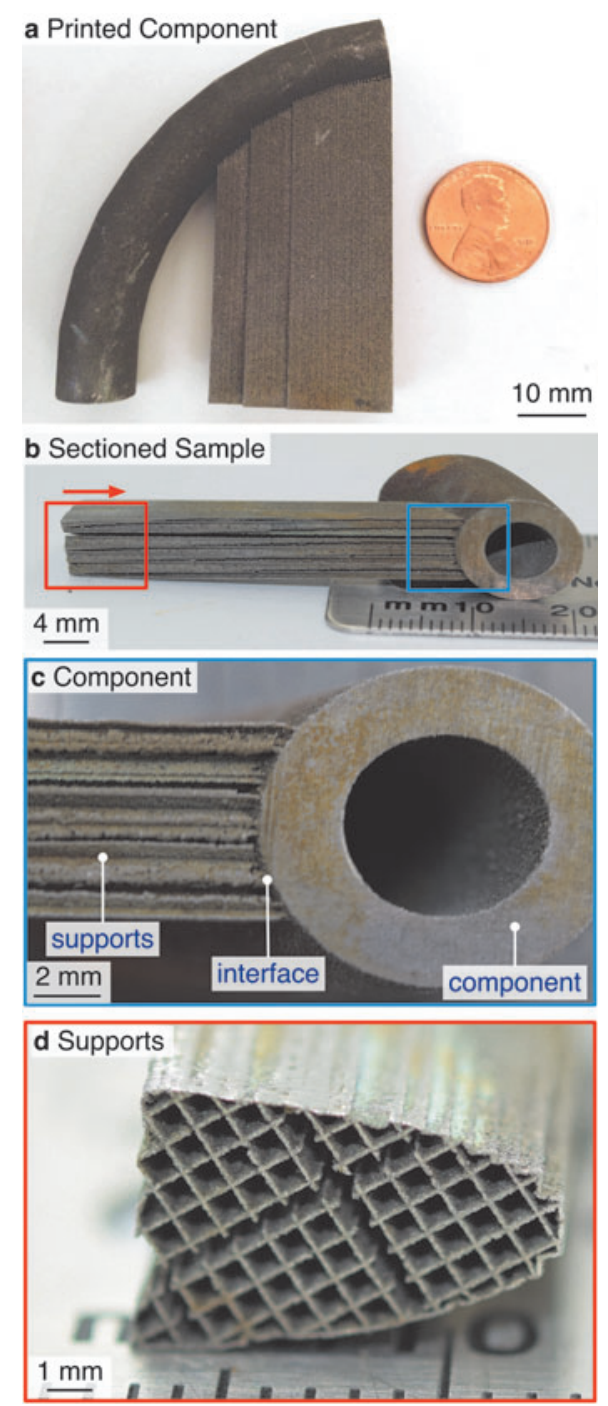

FIG. 1. Optical images illustrating that the supports are very thin relative to the component. (a) Printed component before sectioning into smaller samples; (b) side view of component with supports; (c) higher magnification image highlighting that the supports connect to the component across a small area; (d) cross-section view of the support structure itself. Notice that the support structure consists of an interconnected set of hollow columns only 100$200 \mu \mathrm{m}$ thick.

metals. The sensitization process integrates seamlessly with the standard annealing steps, while its self-terminating nature of the etching process provides high dimensional stability with only minor process control requirements. Details on both processes follow.

\section{Materials and Methods}

\section{Sample fabrication}

Two 17-4 PH tubular arches were fabricated using an EOS M280 PBF printer for this test and smaller samples were cut from these arches for testing. For the direct dissolution experiments, the dimensions were as follows: $11.31 \mathrm{~mm}$ outer diameter (OD), $6.12 \mathrm{~mm}$ inner diameter (ID), and $40 \mathrm{~mm}$ major radius. For the self-terminating sensitized experiments, 
the dimensions were as follows: $8.24 \mathrm{~mm}$ OD, $2.85 \mathrm{~mm}$ ID, and $40 \mathrm{~mm}$ major radius. These dimensions were arbitrary and did not impact the etching process in any notable manner. The tubular arches were fabricated using the manufacturer's recommended processing conditions as follows: $20 \mu \mathrm{m}$ layer thickness with laser power on the order of $195 \mathrm{~W}$, speed of $1 \mathrm{~m} / \mathrm{s}$, hatch spacing of $0.1 \mathrm{~mm}$, and support exposure with a laser power of $75 \mathrm{~W}$ and a speed of $0.6 \mathrm{~m} / \mathrm{s} .^{8}$ The manufacturer's stated composition for the EOS Stainless Steel GP1 powder used in this study is Cr: $15-17.5 \mathrm{wt} . \%$; Ni: $3-5 \mathrm{wt} . \%$; Cu: 3-5 wt.\%; Mn: $\max 1$ wt.\%; Si: $\max 1$ wt.\%; Mo: $\max$ 0.5 wt. \%; Nb: $0.15-0.45$ wt.\%; and Fe: balance. Sample sections $10-13 \mathrm{~mm}$ long were cut from the tubular arch using a $3 \mathrm{~mm}$ thick, water-lubricated, and cooled silicon carbide blade. Care was taken to avoid damaging the support/component interface, and the interface was visually inspected and then its structural integrity verified by trying to pull the supports off by hand. After sectioning, the samples were cleaned in an ultrasonic bath by serially rinsing the sample in deionized (DI) water (18.2 M 2 , Purelab Flex 3), methanol $\left(\mathrm{CH}_{3} \mathrm{OH}, \geq 99.8 \%\right.$; Sigma-Aldrich), acetone $\left[\left(\mathrm{CH}_{3}\right)_{2} \mathrm{CO}\right.$, $\geq 99.5 \%$; BDH Chemicals], and then isopropyl alcohol $\left(\mathrm{C}_{3} \mathrm{H}_{8} \mathrm{O}\right.$, $\geq 99.5 \%$; BDH Chemicals) for $\sim 10$ total minutes. After rinsing, excess fluids were removed using compressed $\mathrm{N}_{2}$. The same cleaning procedure was used immediately before both sensitization and electrochemical testing/etching.

For the self-terminating sensitized sample, a $4.2: 1$ by mass slurry of sodium hexacyanoferrate (II) decahydrate $\left(\mathrm{Na}_{4} \mathrm{Fe}(\mathrm{CN})_{6} \cdot 10 \mathrm{H}_{2} \mathrm{O}, \geq 99 \%\right.$; Alfa Aesar) and deionized water was prepared along with a saturated solution of sodium hexacyanoferrate (II) decahydrate in deionized water. The samples were first dipped in the saturated sodium hexacyanoferrate solution for $20 \mathrm{~min}$ to ensure that the entire surface would be coated with the sensitizing agent. Next, the samples were packed with the slurry and tightly wrapped in high temperature tool wrap (MSC Industrial Supply, 309 stainless steel tool wrap). For these samples, $\sim 0.25 \mathrm{~mol} \mathrm{CN}$ and $\mathrm{H}_{2} \mathrm{O}$ vapor were expected to form during sodium hexacyanoferrate decomposition; this vapor was relieved from the tool wrap by piercing a small, $\sim 0.1 \mathrm{~mm}$ hole in a corner of the tool wrap. The ingress of outside air was expected to be minor with minimal impact on the sensitization process. The thick layer of carbon was observed on the part after sensitization validated this assumption (if $\mathrm{O}_{2}$ ingress was large, then the carbon would have oxidized to $\mathrm{CO}_{2}$ ). The sample was next placed in a silicon carbide box furnace (Lindberg, model C10) at room temperature and then heated to $800^{\circ} \mathrm{C}$ with a ramp rate of $5^{\circ} \mathrm{C} / \mathrm{min}$ and then held there for $6 \mathrm{~h}$. The furnace was then shut off and allowed to slowly cool to room temperature overnight. The sample was removed from the furnace, tool wrap cut away, and residual decomposition products (carbon, sodium) were removed using a stainless steel bristle brush and the cleaning/sonication process detailed previously.

To further test the self-terminating sensitized approach, a set of 316 stainless steel interlocking rings was fabricated using a Concept Laser Metal MLab Powder-Bed Fusion printer. The overall dimensions of each individual ring were as follows: $60 \mathrm{~mm}$ OD, $50 \mathrm{~mm}$ ID, $28 \mathrm{~mm}$ tall, and holes were cut into the 3D model using arbitrarily shaped, close-looped interpolating splines. The interlocking rings were fabricated using the manufacturer's recommended processing condi- tions (not supplied by the manufacturer). Praxair Fe-271-3 powder was used as the stainless steel powder source. The manufacturer's stated composition for the 316 stainless steel used in this study is as follows: Cr: $17.0 \mathrm{wt} . \%$; Ni: $12.0 \mathrm{wt} . \%$; Mo: 2.5 wt.\%; and Fe: balance. This sample was sensitized and etched using the same procedure as the 17-4 $\mathrm{PH}$ samples with minor changes to the electrochemical dissolution hardware. Specifically, the driving potential and current were supplied using an Agilent Technologies N5752A DC power supply with a $1.3 \mathrm{~A}$ current limit and the potential difference between the working electrode (i.e., component) and the reference electrode $(\mathrm{Ag} / \mathrm{AgCl})$ was monitored using an Agilent Technologies U1272A hand-held multimeter.

\section{Electrochemical analysis, dissolution, and metrology}

For the direct dissolution experiments, electrolyte solutions were prepared by mixing nitric acid $\left(\mathrm{HNO}_{3}, 70 \mathrm{wt} . \%\right.$; BDH Chemicals), hydrochloric acid ( $\mathrm{HCl}, 38 \mathrm{wt} . \%$; BDH Chemicals), and deionized water (18 M 2 , PURELAB flex; ELGA) to a final concentration of $0.48 \mathrm{M} \mathrm{HNO}_{3}, 0.1 \mathrm{M} \mathrm{KCl}$, and with $\mathrm{HCl}$ concentrations tested at $0.1,0.5$, and $1.0 \mathrm{M}$. The $\mathrm{KCl}$ increases the base conductivity of the electrolyte solution as well as aiding in the breakdown of the passivation layer. ${ }^{9,10}$ The $\mathrm{HCl}$ employed in the direct dissolution experiments is used to further increase the dissolution rate of the untreated stainless steel. ${ }^{11}$

An electrolyte of $0.48 \mathrm{M} \mathrm{HNO}_{3}$ and $0.1 \mathrm{M} \mathrm{KCl}$ was used for the sensitized surface experiments. Since this experiment was designed to be self-terminating, no $\mathrm{HCl}$ was added. Without the $\mathrm{HCl}$, the dissolution selectivity between the sensitized region and the underlying base component material should be higher. All samples were cleaned with methanol, acetone, and isopropyl alcohol and dried off with $\mathrm{N}_{2}$ gas before submersion in the electrolyte.

A Pine Research Instruments WaveNow USB Potentiostat/Galvanostat was used to measure the open circuit potential (OCP), generate cyclic voltammetry (CV) curves, and apply chronoamperometry tests for the 17-4 PH samples. All potentials were measured relative to a saturated $\mathrm{Ag} / \mathrm{AgCl}$ reference electrode and offset by $+197 \mathrm{mV}$ for reporting results relative to the standard hydrogen electrode (SHE). The reference electrode was electrically/ionically connected to solution through a $4 \mathrm{M} \mathrm{KCl}$ salt bridge with a glass frit located $\sim 3 \mathrm{~cm}$ from the printed sample (midway between the sample and the counter electrode). A $6 \mathrm{~mm}$ diameter graphite rod was used as a counter electrode. After each hour, the sample was removed, imaged using an optical microscope, and its diameter measured using digital calipers (Fowler 4"'/100 mm Economy Digital). A black powder (presumably magnetite, $\mathrm{Fe}_{3} \mathrm{O}_{4}$ ) was observed on the supports. While the powder did not stop the etching process, it did inhibit electrolyte mass transport and reduce the etch rate for a given potential. To alleviate this, the sample was brushed off with a stainless steel bristle brush after imaging and sonicated in isopropanol and then deionized water until the solvents ran clear.

Direct dissolution samples were etched at anodic potentials between +47 and $+97 \mathrm{mV}_{\text {SHE }}$ to generate anodic currents between +60 and $+80 \mathrm{~mA}$. Etching lasted for $7.7 \mathrm{~h}$ until the component separated from the supports and fell to the bottom of the container. The self-terminating sensitized sample was 
etched for $7 \mathrm{~h}$ at potentials between +47 and $+177 \mathrm{mV}_{\mathrm{SHE}}$ to stay within this selective etching region and within the $100 \mathrm{~mA}$ limit of our potentiostat.

Morphology was observed using an Amray 1910 field emission scanning electron microscope (SEM) at $20 \mathrm{kV}$ accelerating voltage and a working distance of $5 \mathrm{~mm}$. Elemental composition was collected using an Apollo XPP energy-dispersive $\mathrm{x}$-ray spectroscopy (EDS) operating at $20 \mathrm{kV}$ and a JXA-8530F Electron Probe Microanalyzer. A Nikon D3300 camera and Dino-Lite Premier model AD7013MTL digital microscope were used to visually record the dissolution process. Macrosurface roughness was measured using a QualiSurf II with a $5 \mu \mathrm{m}$ stylus tip radius over an $8 \mathrm{~mm}$ length of the sample surface located parallel to the build direction.

\section{Results and Discussion}

\section{Direct dissolution of PBF supports}

To demonstrate the direct dissolution approach, samples were sectioned from a PBF-printed 17-4 PH stainless steel tubular arch printed using the manufacturer's standard processing parameters. Samples were immersed in solutions containing $0.48 \mathrm{M} \mathrm{HNO}_{3}, 0.1 \mathrm{M} \mathrm{KCl}$, and $\mathrm{HCl}$ at concentrations of $0.1,0.5$, or $1.0 \mathrm{M}$. Next, the sample surface was stripped under cathodic conditions for $1 \mathrm{~min}$ at $-10 \mathrm{~mA} / \mathrm{cm}^{-2}$ and then OCP was collected for $10 \mathrm{~s}$ and then for $1 \mathrm{~h}$. CV curves were collected for the OCP and plotted as potentiodynamic polarization curves in Figure 2. For reference, the measured OCP and corrosion potential, $E_{c o r r}$, are listed in Supplementary Table S1 in Supplementary Data (Supplementary Data are available online at www.liebertpub.com/ $3 \mathrm{dp}$ ). As expected, these curves show that increasing the $\mathrm{HCl}$ concentration lowers $E_{c o r r}$, while increasing the dissolution rate. ${ }^{11}$ The $\mathrm{HCl}$ concentration was set to $1.0 \mathrm{M}$ for the direct dissolution etching experiments. The 17-4 PH stainless steel sample was electrochemically etched at anodic potentials between +47 and $+97 \mathrm{mV}_{\text {SHE }}$ to keep the anodic current

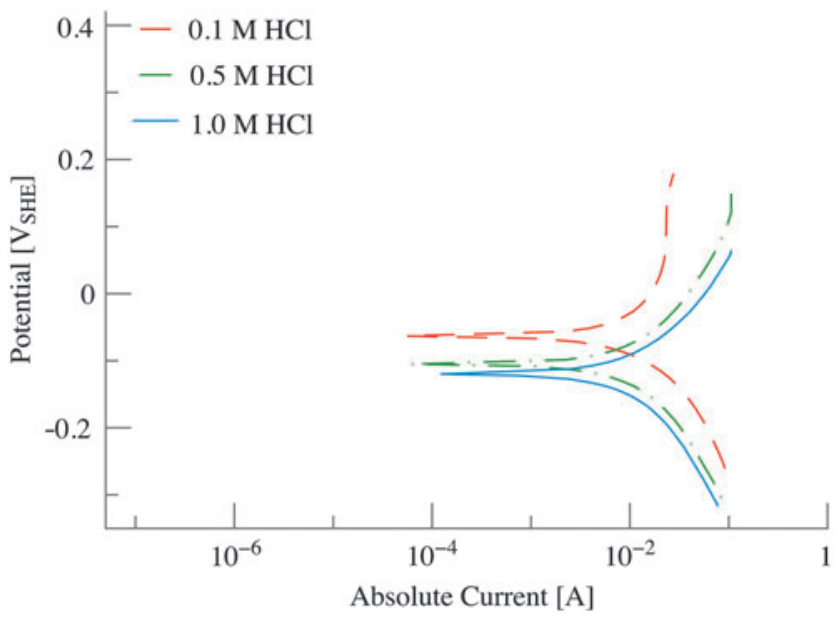

FIG. 2. Potentiodynamic polarization curves for the direct dissolution of unsensitized 17-4 PH stainless steel in an electrolyte containing $\mathrm{HNO}_{3}(0.48 \mathrm{M})$ and $\mathrm{KCl}(0.1 \mathrm{M})$ at various $\mathrm{HCl}$ concentrations showing how $E_{\text {corr }}$ decreases with increasing $\mathrm{HCl}$. $1.0 \mathrm{M} \mathrm{HCl}$ was selected for direct dissolution experiments. between +60 and $+80 \mathrm{~mA}$. Every hour, the sample was removed from the electrolyte, imaged using an optical microscope, its diameter measured using digital calipers, and sonicated in isopropanol. Etching lasted for $7.7 \mathrm{~h}$ until the component separated from the supports and fell to the bottom of the container.

The optical images in Figure 3 depict the sample at various stages of the process; all scale bars are $3 \mathrm{~mm}$ long. The component is the cylindrical structure on the right and the supports are the linear structures to the left. Notice that the supports connect to the component across a very small interface, $130 \mu \mathrm{m}$ wide. After etching, the sample surface felt, by hand, extremely rough and " prickly.' SEM images in Supplementary Figure S2 (Supplementary Data) show the change in the surface before and after the etching. Compared to the original surface, the direct dissolution sample shows significant pitting across multiple length scales.
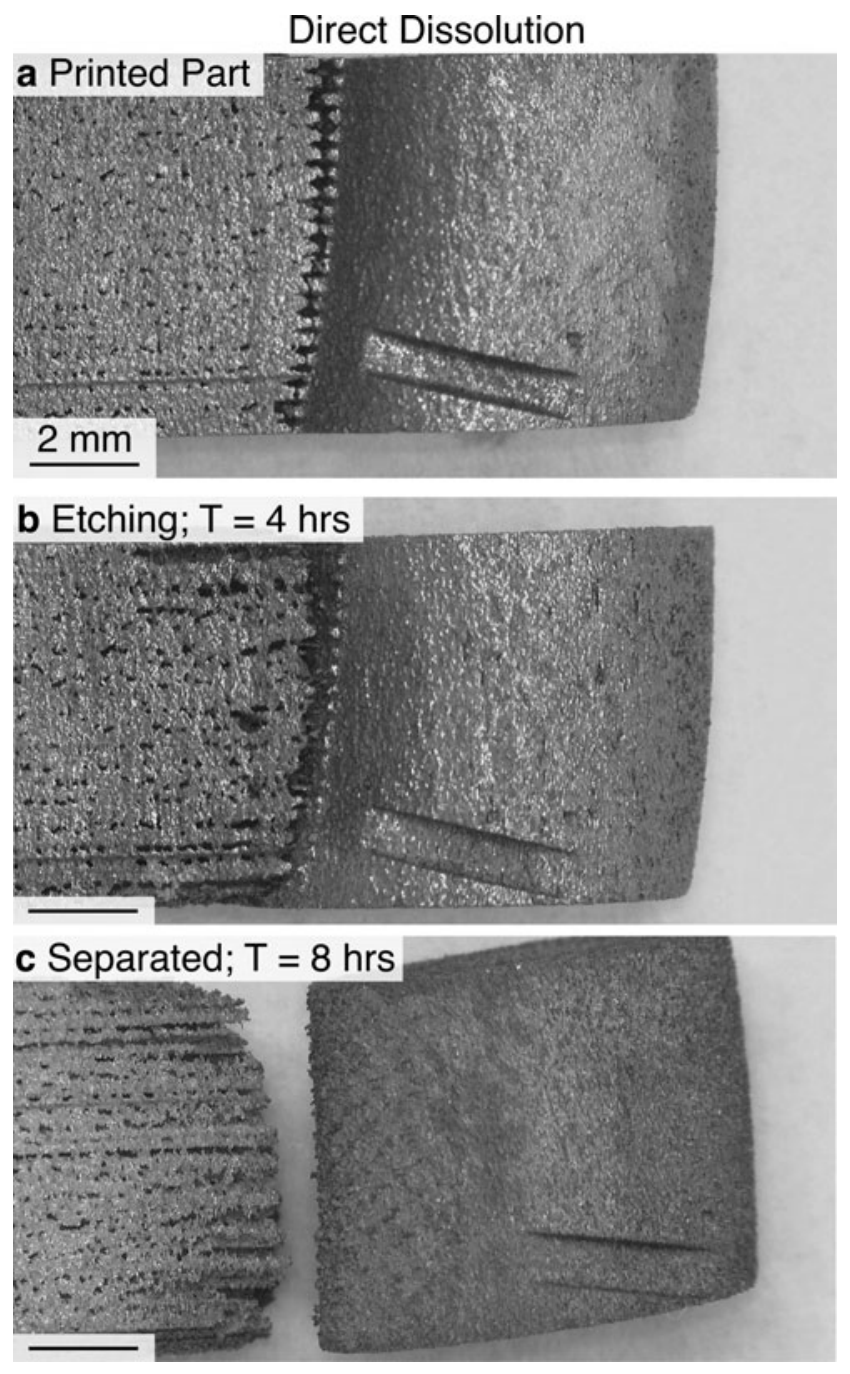

FIG. 3. Optical images of direct dissolution sample (a) before; (b) during; and (c) after electrochemical separation. Notice that the surface visibly roughens during the direct dissolution process. The SEM images in Figure S1 show that this roughness extends across multiple length scales for the direct dissolution process. SEM, scanning electron microscope. 
Figure 4 plots the measured outer diameter and surface material lost $(\Delta R)$ versus etch time for the direct dissolution sample. This dissolution process removed $120 \mu \mathrm{m}$ of material from the component's surface. Notice that the rate of dissolution is roughly linear and shows no signs of slowing after $7 \mathrm{~h}$ of electrochemical etching. While the direct dissolution process is slightly simpler (e.g., it does not require additives during the annealing step), the dimensional accuracy of large or complex components is likely to suffer because the entire component will continue to etch until every last support is removed.

\section{Sensitized, self-terminating dissolvable supports}

To demonstrate the self-terminating, dissolvable support process, the 17-4 PH stainless steel samples were sensitized using sodium hexacyanoferrate during the annealing step $\left(800^{\circ} \mathrm{C}\right.$ for $\left.6 \mathrm{~h}\right)$. The sodium hexacyanoferrate decomposes to release carbon and nitrogen species that diffuse into the printed stainless steel sample and react to precipitate chromium carbides and nitrides. ${ }^{11,12}$ This sensitizing process reduces the free chromium content within the top 100-200 $\mu$ m of the sample to below the threshold necessary to form a stable, protective layer of chromium oxide. Since the support structures are only $\sim 150 \mu \mathrm{m}$ thick, they are readily dissolved under a bias in nitric acid solution, while the surface of the component is only etched until the underlying stainless steel component material is revealed. The carbon concentration was measured using EnergyDispersive X-ray Spectroscopy (EDS) to verify that carbon is diffusing into the sample across the desired depth of 100 $200 \mu \mathrm{m}$. For reference, Supplementary Data plots these data in Supplementary Figure S3 along with a brief discussion on the diffusion of carbon in these materials.

Similar to the direct dissolution tests, OCP and CV experiments were gathered for the sensitized 17-4 PH stainless steel sample. The potentiodynamic polarization curves of the sensitized sample at various stages are shown in Figure 5. These data show that there is a $410 \mathrm{mV}$ window (+356 to $\left.-54 \mathrm{mV}_{\mathrm{SHE}}\right)$ where the sensitized region will experience anodic corrosion, while the component material would be

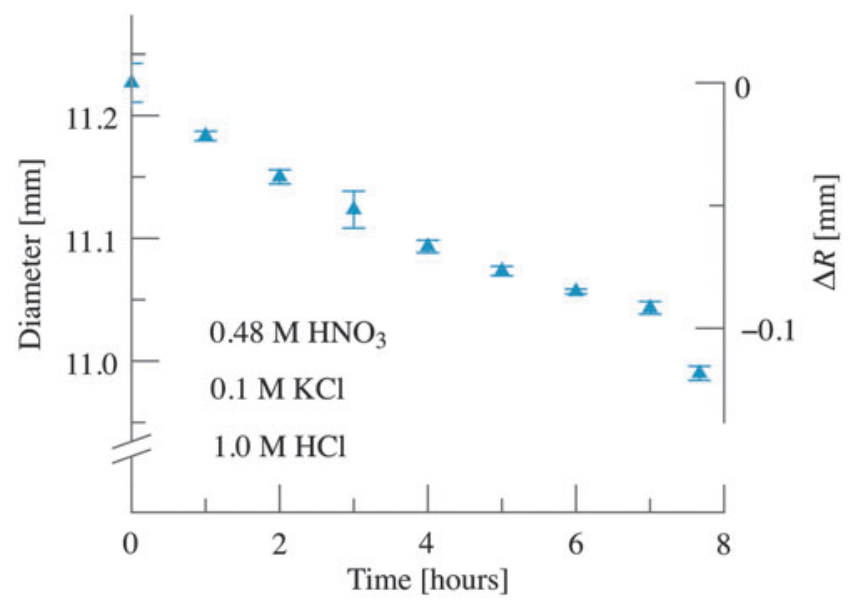

FIG. 4. Plot of component diameter and change in radius $(\Delta R)$ throughout direct dissolution process of 17-4 PH stainless steel. One hundred twenty micrometers of material were removed from the component surface. Notice that the unsensitized sample has a linear slope indicating continuous material loss.

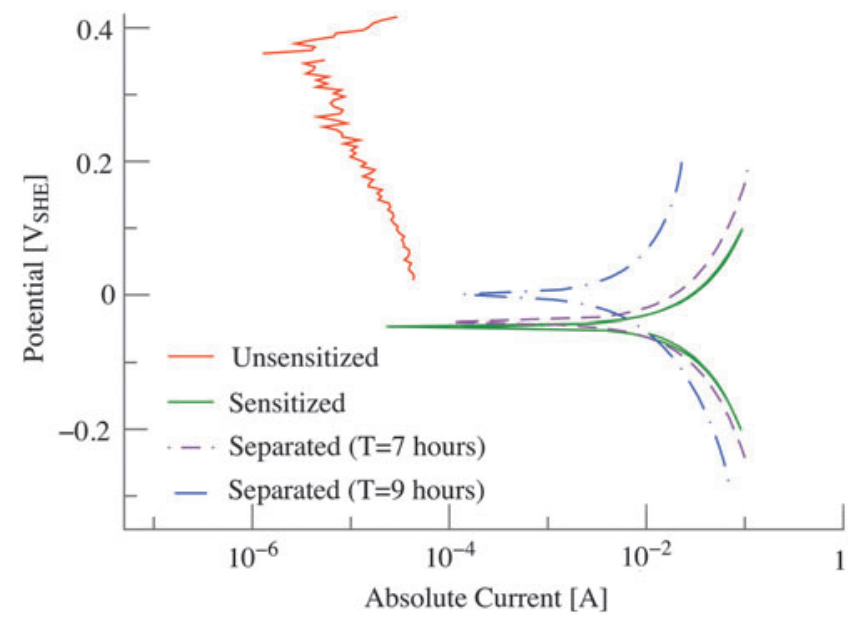

FIG. 5. Potentiodynamic polarization curves of the selfterminating, sensitized 17-4 PH stainless steel sample at various times during the etching process in an electrolyte containing $\mathrm{HNO}_{3}(0.48 \mathrm{M})$ and $\mathrm{KCl}(0.1 \mathrm{M})$. Sensitizing the sample drops the $E_{\text {corr }}$ from $+357 \mathrm{mV}_{\text {SHE }}$ down to $-57 \mathrm{~m}$ $\mathrm{V}_{\text {SHE }}$, providing a wide processing window for selectively etching. SHE, standard hydrogen electrode.

under protective cathodic bias. The sensitized sample was etched for $7 \mathrm{~h}$ at potentials between +47 and $+177 \mathrm{mV}_{\text {SHE }}$ to stay within this selective etching region and within the $100 \mathrm{~mA}$ limit of our potentiostat. As before, the sample was removed from the electrolyte every hour, imaged using an optical microscope, its diameter measured using digital calipers, brushed clean, and then sonicated in isopropanol. Etching lasted for $7 \mathrm{~h}$, and the component separated from the supports during brushing.

The optical images in Figure 6 show the sample at various stages of the process; all scale bars are $3 \mathrm{~mm}$ long. As before, the component is the cylindrical structure on the right of the image, and the supports are the linear structures to the left. After heat treatment (Fig. 6b), the part darkens in color, and some residual carbonous material covers up the voids at the component/support interface. This material was removed before etching to increase electrolyte contact and corrosion at the support/component interface (Fig. 6c). For this work, we elected to scrub the surface using a stainless steel brush and sonicate the component in DI water; future work will examine the impact of oxidizing the carbon away. In addition, the excess carbonous material quickly fell away during etching as the underlying sensitized surface was etched away. Between Figure 6d and e, the component color changes from black to silver/steel, while the support structure is still black. This suggests that most of the sensitized region has been removed from the component material. However, some residual sensitized material did remain on the sample surface after support separation. The potentiodynamic polarization plot (Fig. 5) of the component immediately after separation ( $\mathrm{T}=7 \mathrm{~h}$, purple, long dash) shows that the corrosion potential of the separated component is still very close to the sensitized sample (green, solid). A section of the component was subject to anodic etching for an additional $2 \mathrm{~h}$ before $E_{\text {corr }}$ started to noticeably increase (blue, long dash). This remnant sensitization can be avoided with further optimization of the sensitization schedule (i.e., temperature, time). 

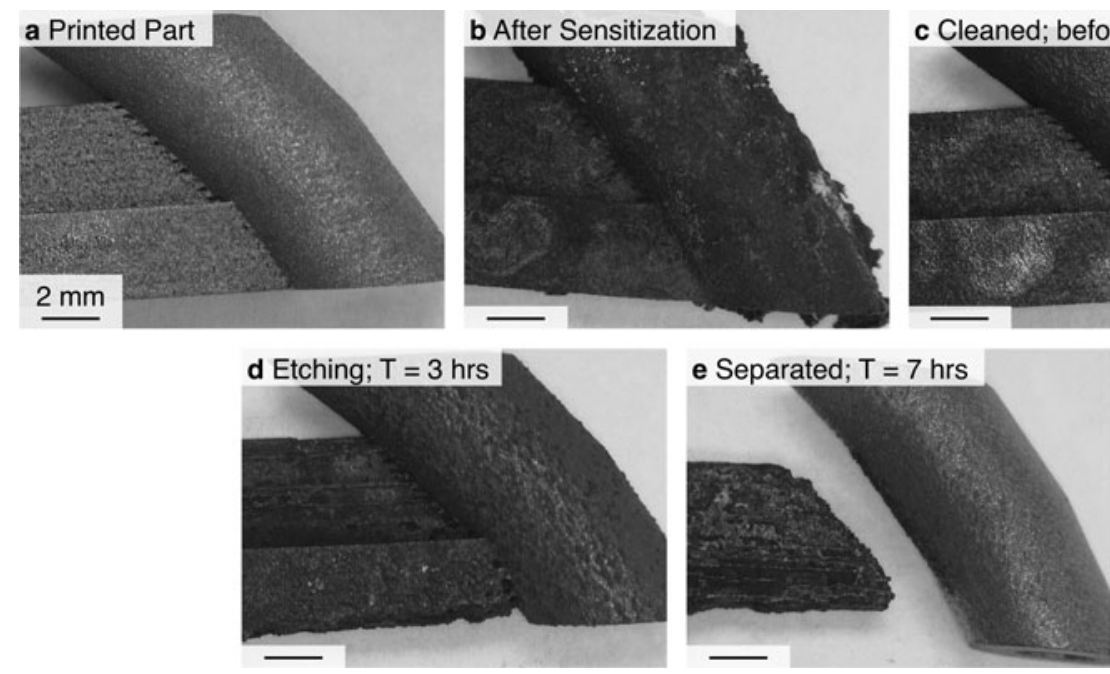

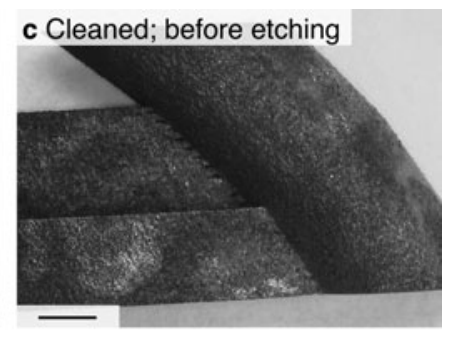

.

FIG. 6. Optical images of the sensitized 17-4 PH stainless steel sample (a) as printed; (b) after sensitization; (c) after cleaning; (d) during etching, $\mathrm{T}=3 \mathrm{~h}$; (e) separation complete, $\mathrm{T}=7.7 \mathrm{~h}$.

Figure 7 plots the measured outer diameter and surface material lost $(\Delta R)$ versus etch time for the self-terminating, sensitized 17-4 PH stainless steel sample. Unlike the direct dissolution sample, the rate of diameter change for the sensitized sample continues to decrease over time, stopping just short of its asymptote before the component separated from its supports. This indicates that the sensitization step successfully creates a self-limiting dissolution process. In comparison to the direct dissolution process that lost $120 \mu \mathrm{m}$ of material off its surface, the self-limiting sample lost slightly more material, $200 \mu \mathrm{m}$. Optimizing the carbon diffusion depth by adjusting annealing temperature, annealing time, or carbon source and concentration could reduce the amount of surface material removed through this self-limiting approach. In addition, the surface of the self-limiting sample shows significantly less pitting compared to the direct dissolution approach (Supplementary Fig. S1).

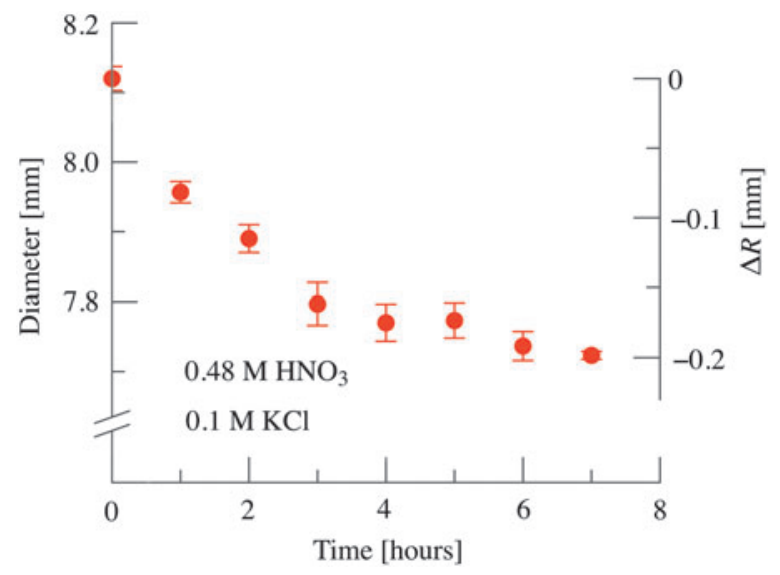

FIG. 7. Plot of component diameter and change in radius $(\Delta R)$ throughout dissolution process for the sensitized 17-4 $\mathrm{PH}$ stainless steel. Two hundred micrometers of material were removed from the component surface. The material loss for the sensitized sample over time decreases asymptotically, verifying that the process is self-terminating.
Surface roughness measurements before and after etching were taken to quantify the impact that the direct dissolution and sensitization/self-limiting approaches have on surface finish. The results are shown in Table 1 , where $R_{q}$ is the root mean square deviation of the profile, $R_{p}$ is the maximum measured profile peak, and $R_{v}$ is the maximum measured valley depth. From these measurements, it is clear that both dissolution processes reduce the surface roughness of the sample. Future work will examine the impact of both sensitization and etching parameters on surface roughness to further decrease postprocess sample roughness.

The sectioned tubular samples demonstrated that the selfterminating sensitization process works, the supports are completely removed with little change in component size. To further demonstrate the utility of this approach, a larger, more complicated component was designed, fabricated, and sensitized using the same conditions as the 17-4 PH stainless steel samples, and then the supports dissolved using the selfterminating sensitization approach. Shown in Figure 9, each ring is $\sim 60 \mathrm{~mm}$ in diameter and includes complicated holes designed using interpolated splines along with variable radii fillets. The two rings were arranged to be interlocking during build layout. This component was designed to be difficult to machine and further illustrate the potential impact that dissolvable metal supports could have on metals additive manufacturing. An informal quote from ASU's machine shop estimated that it would take them 32 to $40 \mathrm{~h}$ to remove the supports with $200 \mu \mathrm{m}$ accuracy. With hourly costs for machine shops ranging from $\$ 30 / \mathrm{h}-\$ 100 / \mathrm{h}$ (ASU

Table 1. Table Comparing Surface Roughness of Samples Before and After Etching

\begin{tabular}{lccc}
\hline Sample & $\mathrm{R}_{\mathrm{q}}(\mu m)$ & $\mathrm{R}_{\mathrm{p}}(\mu m)$ & $\mathrm{R}_{\mathrm{v}}(\mu m)$ \\
\hline Original/unprocessed & 0.97 & 1.65 & 1.90 \\
Direct dissolution & 0.65 & 1.11 & 1.76 \\
Sensitized/self-terminating & 0.6 & 1.23 & 1.34 \\
\hline
\end{tabular}

Notice that both dissolution processes reduce surface roughness. 


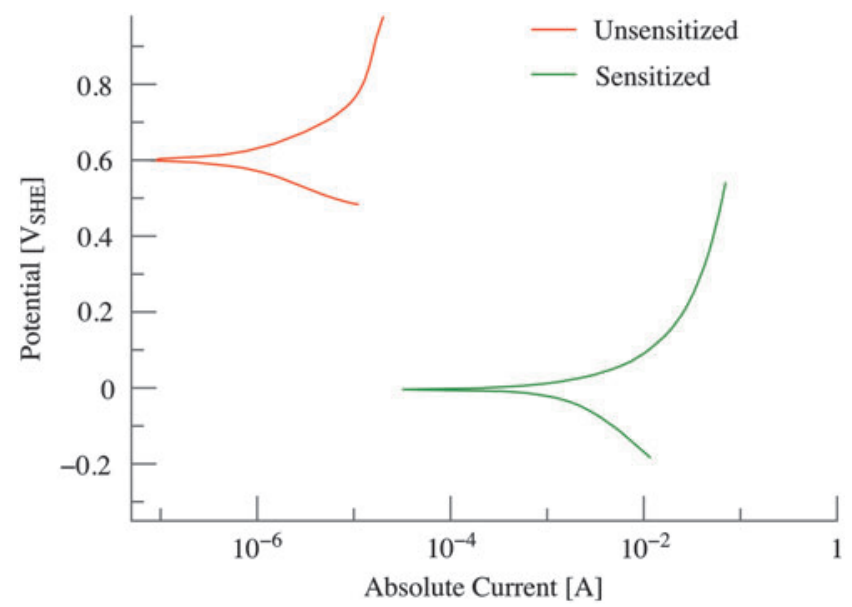

FIG. 8. Potentiodynamic polarization curves of the selfterminating, sensitized 316 stainless steel before (unsensitized, red line) and after sensitization (sensitized, green line) in an electrolyte containing $\mathrm{HNO}_{3}(0.48 \mathrm{M})$ and $\mathrm{KCl}(0.1 \mathrm{M})$. Sensitizing the sample drops the $E_{\text {corr }}$ from $+600 \mathrm{mV}_{\mathrm{SHE}}$ down to $0 \mathrm{mV}_{\mathrm{SHE}}$, providing a wide processing window for selectively etching.

internal rate vs. local machine shops), it would cost between $\$ 900$ and $\$ 4000$ to remove the support structures from a part with this level of complexity.

316 stainless steel was used for this component to demonstrate the flexibility of the sensitization approach. As with the 17-4 PH stainless steel, potentiodynamic polarization curves were collected to identify an operating window where the sensitized surface would experience anodic corrosion, while the underlying component material was cathodically

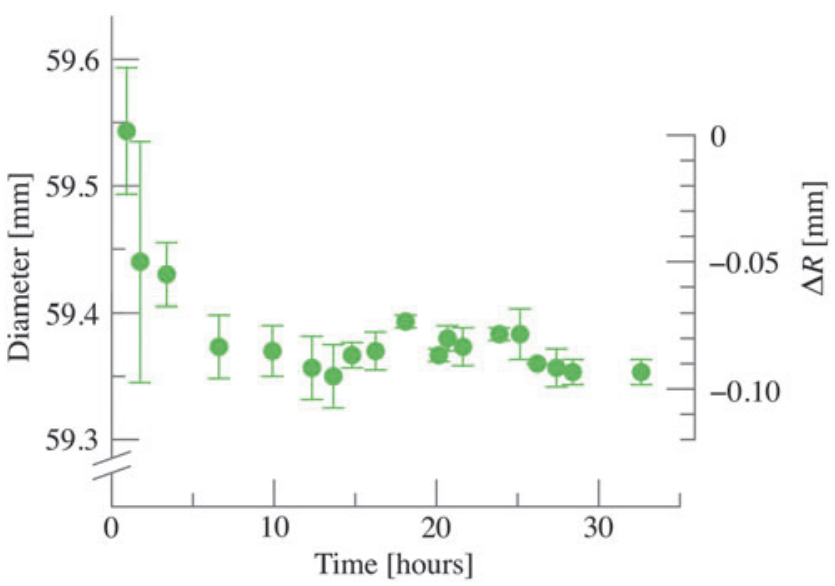

FIG. 10. Plot of interlocking ring diameter and change in radius $(\Delta R)$ throughout dissolution process for the sensitized 17-4 PH stainless steel. Slightly less than $100 \mu \mathrm{m}$ of material were removed from the component surface. After $2 \mathrm{~h}$, the component diameter does not decrease and only $\sim 85 \mu \mathrm{m}$ of material were removed from the component surface. Note, error bars mark the range of measurements recorded for each data point.

protected. The electrolyte was $0.48 \mathrm{M} \mathrm{HNO}_{3}$, and $0.1 \mathrm{M} \mathrm{KCl}$. Plotted in Figure 8 , these potentiodynamic polarization curves show that sensitization reduces $E_{\text {corr }}$ from +600 to $0.0 \mathrm{mV}_{\mathrm{SHE}}$. For the support dissolution process, the electrolyte composition was kept the same and replaced every $2-5 \mathrm{~h}$ depending on how discolored the electrolyte was; the applied potential was kept between +200 and $+400 \mathrm{mV}_{\text {SHE }}$ with measured currents typically between 0.8 and $1.0 \mathrm{~A}$ until the
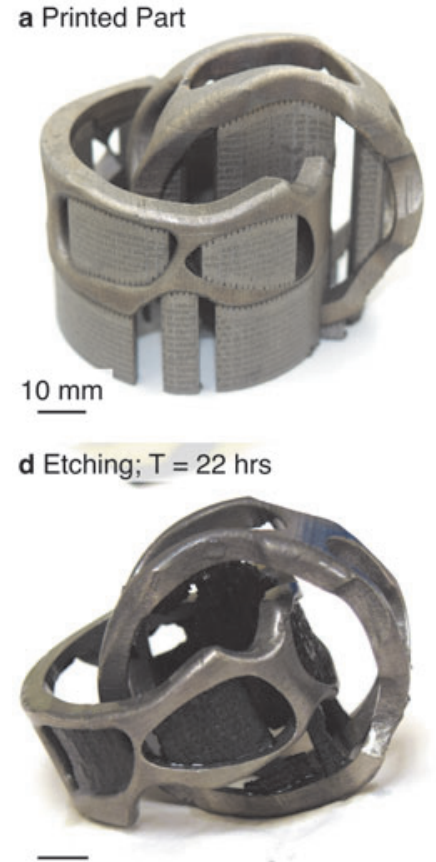

b After Sensitization

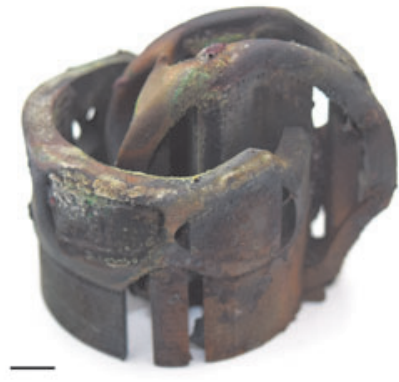

e Separated; $\mathrm{T}=32.5 \mathrm{hrs}$

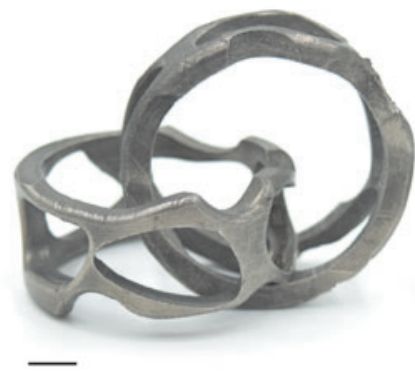

c Etching; $\mathrm{T}=7 \mathrm{hrs}$

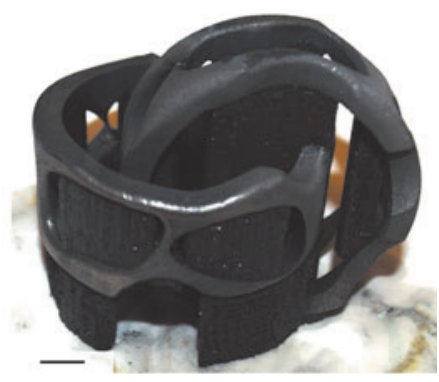

f

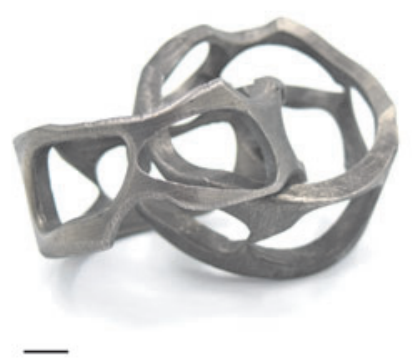

FIG. 9. Optical images of interlocking stainless steel rings. (a) As printed component was cut from the build platform; (b) after sensitization; (c) after etching for $7 \mathrm{~h}$; (d) after etching for $22 \mathrm{~h}$ the rings have separated from one another; (e, f) supports completely removed at $32.5 \mathrm{~h}$. Notice that the component geometry is largely unchanged even though a large amount of support material was dissolved. 
end of the dissolution process when the current steadily dropped as the last bits of sensitized regions were depleted.

Using the self-terminating sensitization approach, we were able to completely dissolve the supports in $32.5 \mathrm{~h}$ with less than $100 \mu \mathrm{m}$ of material removed from the component surface. Etch time could have been reduced if a power supply with a larger current limit was used. Figure $9 \mathrm{a}-\mathrm{f}$ show the part as printed, after sensitization, and throughout the etching progresses until the supports are completely removed. Notice that this process is reasonably fast, requires very little intervention or skilled labor, and the etching process does not significantly change component dimensions.

The diameter of one of the rings was periodically measured throughout the etch process to show that the process is selfterminating and the component is dimensionally stable even for long etch times. Figure 10 plots this measured diameter and change in radius over time. Notice that the sensitized surface is quickly removed with no change in diameter observed after the first few hours; any variation in measured diameter after $3 \mathrm{~h}$ is largely attributed to the variations in measurement location.

The overall etch time of $32.5 \mathrm{~h}$ was two to three times longer than the previous tests with the 17-4 PH stainless steel tubular arch. Some of this increase can be attributed to the increased surface area of the interlocking rings relative to the much smaller tubular arch. This increase in area resulted in a lower overall current density even though the applied current was $\sim 10 \times$ higher. However, we attribute the majority of the etch time increase to powder trapped within the closed support structures. Notice in Figure 9c that the majority of open-ended supports (i.e., those that were cut when the component was separated from the build platform) have been dissolved by the 12-16 h marks. In contrast, the supports that remained closed (i.e., those supporting internal holes within the rings) still appear complete. These "closed supports" are being etched and their thickness was visually observed to continuously decrease, but the rate was $\sim 1 / 2$ to $1 / 4$ the rate of opened supports. In addition, the opened supports rapidly became brittle and fragile during the etching process and could be pierced by a set of tweezers by the 10th hour of etching. This stands in sharp contrast to the closed supports that were mechanically robust throughout most of the etching process. A likely explanation for these important differences is that the powder trapped within the opened supports was removed during the presensitization cleaning, while the closed supports retained their trapped powder. In fact, significant amounts of powder were observed to leave the component during the presensitization sonication cleaning. The powder trapped within the closed supports increases the volume of material that must be dissolved as part of the support dissolution process without increasing the readily available exposed surface area available for electrochemical dissolution. We classify that the trapped powder is not available for electrochemical dissolution because, while it is likely to be fluid accessible, the long and tortuous diffusion path is likely to restrict electrochemical dissolution within the interior. As a result, the closed supports effectively act as solid structures from an electrochemical view and the low surface to volume ratio combined with an increased volume of material results in a longer etch time. Even though the etch time was longer, the trapped powder did dissolve without any need to increase the applied potential; this indicates that the powder was sensitized during the sensitization process and is fluid accessible.
Overall, this approach significantly simplifies postprocessing of PBF-printed metals. It replaces complicated and expensive machining operations with simple electrochemical baths that could, in theory, be left unattended for extended periods of time with little impact to component dimensions. In addition, we expect our self-terminating approach to be particularly useful for batch processing entire build platforms, smoothing surfaces, and maintaining component dimensional accuracy. While closed versus opened support structures showed an increase in etching time, the self-terminating nature of the process means that the component's overall geometry was not effected and the process could likely be completed with minimal supervision.

\section{Conclusions}

In conclusion, we demonstrate, for the first time, that support structures in PBF-printed materials can be selectively removed using novel approaches for both direct dissolution and self-terminating electrochemical etching. This electrochemical process will drastically reduce the complexity, costs, and time associated with support removal by replacing laborious machining and grinding operations with a simple sensitization and etching processes. The sensitization process has been designed to be easily integrated into the normal thermal annealing step used to reduce internal stresses, while the etching process has been designed to be self-terminating and easy to apply. These novel processes simplify support removal and provide an approach to dissolve metallic supports similar to polymer-based additive manufacturing.

\section{Acknowledgments}

O.J.H. gratefully acknowledges funding for this project provided by Science Foundation Arizona for BSP 0615-15. The interlocking rings were generously supplied by Keng Hsu and Anagh Deshpande of the Polytechnic School Manufacturing Research and Innovation Hub and the Advanced Multi-scale Manufacturing Laboratory. Simpson gratefully acknowledges funding provided by CIMP-3D. Materials and machine time were provided by the Center for Innovative Materials Processing through Direct Digital Deposition (CIMP-3D) at Penn State University.

\section{Author Disclosure Statement}

No competing financial interests exist.

\section{References}

1. Griffith ML, Harwell LD, Romero J. Multi-material processing by LENS. Proceedings of the Solid Freeform Fabrication Symposium, 1997, Austin, TX, p. 387.

2. Di Wang, Yang Y, Yi Z, Su, X. Research on the fabricating quality optimization of the overhanging surface in SLM process. Int J Adv Manuf Technol 2013;65:1471-1484.

3. Domonoky; BonsaiBrain. Support-Full Disclosure. http:// ifeelbeta.de/index.php/support/support-full-disclosure (accessed August 5, 2016).

4. Hildreth OJ, Nassar AR, Chasse KR, Simpson TW. Dissolvable metal supports for 3D direct metal printing. 3D Print Addit Manuf 2016;3:90-97.

5. Gibson I, Rosen DW, Stucker B. Additive Manufacturing Technologies; 1st ed. Boston, MA: Springer US, 2010. 
6. Vanýsek P. Impact of electrode geometry, depth of immersion, and size on impedance measurements. Can $\mathrm{J}$ Chem 1997;75:1635-1642.

7. Zhang F, Liu J, Ivanov I, Hatzell MC, Yang W, Ahn Y, et al. Reference and counter electrode positions affect electrochemical characterization of bioanodes in different bioelectrochemical systems. Biotechnol Bioeng 2014;111: 1931-1939.

8. Starr TL, Rafi K, Stucker B, Scherzer CM. Controlling phase composition in selective laser melted stainless steels. Proceedings of the Solid Freeform Fabrication Symposium, 2012, Austin, TX, pp. 439-446.

9. Epstein JA, Levin I, Rabinovitz E, Raviv S. Cathodic corrosion of stainless steel in nitric acid. Corr Sci 1965;5:461-470.

10. Streicher MA. Pitting corrosion of $18 \mathrm{Cr}-8 \mathrm{Ni}$ stainless steel. J Electrochem Soc 1956;103:375-390.
11. Noor EA, Al-Moubaraki AH. Corrosion behavior of mild steel in hydrochloric acid solutions. Int J Electrochem Sci 2008;3:806-818.

12. Turpin T, Dulcy J, Gantois M. Carbon diffusion and phase transformations during gas carburizing of high-alloyed stainless steels: Experimental study and theoretical modeling. Metall Mat Trans A 2005;36:2751-2760.

Address correspondence to: Owen J. Hildreth

School for Engineering Matter, Transport, and Energy Arizona State University

PO Box 876106

Tempe, AZ 85287-6106

E-mail: owen.hildreth@asu.edu 